\title{
Causes of pneumonia presenting to a district general hospital
}

\author{
RJ WHITE, AD BLAINEY, K JOY HARRISON, SKR CLARKE \\ From the Departments of Medicine and Bacteriology, Frenchay Hospital, and the Public Health Laboratory, \\ Bristol
}

ABSTRACT The incidence of bacterial, viral, mycoplasma, and rickettsial infections has been assessed prospectively in 210 adult patients with pneumonia who presented to a district hospital over a six-year period. One hundred and thirteen infective agents were detected in 103 patients. The agent most frequently detected was Mycoplasma pneumoniae which accounted for 30 infections. A bacterial pathogen was found in 43 patients. Streptococcus pneumoniae was the most common of these (24 patients); Staphylococcus aureus (eight), Haemophilus influenzae (four), Klebsiella spp (three), and Legionella pneumophila (three) were all less common. Chlamydial or rickettsial infections (Psittacosis or $\mathrm{Q}$ fever) were detected in nine patients. Viral infections were found in 31 patients (22 influenza A, four influenza B, two parainfluenza, and three respiratory syncytial virus). There were 10 patients in whom more than one pathogen was identified. In 107 patients no pathogens could be identified. Seventy-five per cent of these patients had either received antibiotics before entering hospital, or were unable to produce any sputum for culture. The incidence of bacterial pneumonia has probably therefore been underestimated. Nevertheless this survey does emphasise the importance of $M$ pneumoniae as a pathogen in patients with pneumonia presenting to hospital.

The last major survey of adult patients with pneumonia presenting to hospital in Britain was that of Bath et $a l^{1}$ in 1962. Since then, developments in diagnostic techniques have improved the detection of the "non-bacterial" pneumonias, particularly mycoplasma pneumonia, and newly-discovered organisms, such as Legionella pneumophila, have been recognised as pathogens in primary pneumonia. ${ }^{2}$ Although other series incorporating these techniques have been published, the majority have been compiled in the United States of America and their conclusions may not necessarily be applicable to this country.

The present survey is a 75-month prospective study of adult pneumonia acquired in the community and presenting to a general hospital. It was designed to assess any changes in the pattern of pneumonia pathogens that may have taken place over the last 20 years, and to establish the frequency of infection with pathogens that have been less readily detected in the past.

\section{Methods}

All patients admitted to this hospital with a clinical diagnosis of primary pneumonia between January

Address for reprint requests: Dr RJ White, Department of Medicine, Frenchay Hospital, Bristol BS16 1LE.
1974 and March 1980 were considered for inclusion in the study. All patients had a history of acute pneumonia and had radiological evidence of consolidation. Those in whom pneumonia was secondary to intercurrent illness (such as aspiration pneumonia after stroke or coma), and patients in whom the pulmonary consolidation was later found to be caused by pulmonary embolism, bronchopulmonary aspergillosis, or tuberculosis were excluded. Two hundred and ten patients remained for analysis; $138(66 \%)$ were male and $72(34 \%)$ were female. The mean age of the patients was 54 years (range 12-100 yr).

All specimens were processed according to the routine procedures used in the laboratory of this hospital. Blood and sputum specimens were collected from the patients as soon as possible after admission, usually on the first hospital day. A representative sample of sputum was homogenised by mechanical means with an equal volume of Ringer's solution, and an aliquot of this used to make a final dilution of 1 in 5000 in normal saline; $0.01 \mathrm{ml}$ of this was then cultured on CLED medium and on blood agar streaked with Staphylococcus aureus to reveal haemophilus by satellitism. Both plates were incubated in $10 \% \mathrm{CO}_{2}$ for at least 18 hours. More than 10 bacterial colonies of a single 
organism on either plate were considered evidence of the involvement of that organism in the aetiology of pneumonia.

Blood cultures were taken into Brewer's medium and glucose broth, and incubated at $37^{\circ} \mathrm{C}$. Subcultures were made on days 1,2 , and 7 .

Throat swabs were collected on the morning after admission from those patients whose illness had lasted less than five days, and were transported to the laboratory in milk saline medium within six hours of collection. Blood was taken from patients on the day of admission, and a second sample taken between 14 and 21 days. If the patient had already been ill for more than 21 days, a single sample was sent.

Throat swabs were inoculated into monkey kidney, HeLa cell, and human embryo fibroblast cell cultures, and isolates identified by immunofluorescence. Sera were examined by complement fixation against influenza $\mathrm{A}$ and $\mathrm{B}$, parainfluenza 1 and 3, respiratory syncytial virus (RSV), adenovirus, psittacosis, Coxiella burneti and Mycoplasma pneumoniae, and by immunofluorescence for antibodies to Legionella pneumophila with the Pontiac strain formolised yolk sac antigen supplied by the Division of Microbiological Reagents of the Central Public Health Laboratory. Sera for testing for antibody to $L$ pneumophila were available only from 1976 onwards (39 months). A significant result in all serological tests was taken as a fourfold or greater rise of antibody, or a convalescent antibody titre of 256 or greater.

\section{Results}

One hundred and thirteen infecting agents were detected in 103 patients (table 1) with nine mixed bacterial/viral infections and one bacterial/rickettsial infection.

Satisfactory sputum specimens were obtained from 133 patients $(63 \%)$; bacterial pathogens were cultured from 43 of these. In 87 patients $(37 \%)$ sputum was not obtained. The reasons were that the patients were too ill, were uncooperative, or that no sputum was being expectorated. Transtracheal aspiration and other methods of obtaining sputum were not attempted. Only $45 \%$ of the patients with a "nonbacterial" pneumonia-that is, mycoplasma pneumonia, psittacosis, and $Q$ fever-could produce sputum for culture. In the 107 patients in whom no pathogens were detected, sputum was obtained from $59 \%$.

The organism most commonly identified was Streptococcus pneumoniae (24 patients) followed by Staph aureus (eight). Haemophilus influenzae (four) and Klebsiella spp (three) were both uncommon. A viridans streptococcus was grown on blood culture
Table 1 Agents identified in primary pneumonia

\begin{tabular}{lcc}
\hline Organism & Number & Percentage \\
\hline Bacterial pneumonia & & \\
Streptococcus pneumoniae & 24 & $11 \cdot 5$ \\
Staphylococcus aureus & 8 & 4 \\
Haemophilus influenzae & 4 & 2 \\
Klebsiella spp & 3 & $1 \cdot 5$ \\
Viridans streptococcus* & 1 & $0 \cdot 5$ \\
Legionella pneumophila $\dagger$ & 3 & $1 \cdot 5$ \\
Total of bacterial pneumonias & 43 & $20 \cdot 5$ \\
"Non-bacterial" pneumonia & & \\
Mycoplasma pneumoniae & 30 & 14 \\
Chlamydia psittaci & 3 & $1 \cdot 5$ \\
Coxiella burneti & 6 & 3 \\
Total of non-bacterial pneumonias & 39 & $18 \cdot 5$ \\
& & \\
Virus infections & & \\
Influenza A & 22 & $10 \cdot 5$ \\
Influenza B & 4 & 2 \\
Parainfluenza & 2 & 1 \\
Respiratory syncytial virus & 3 & $1 \cdot 5$ \\
Total of virus infections & 31 & 15 \\
No identifiable pathogen & 107 & 52 \\
\hline
\end{tabular}

*Isolated on blood culture.

†Sera from 1976-80 only.

in one patient. Although coliform organisms were isolated from the sputum of three patients, all of these had received broad spectrum antibiotics before sputum was obtained, and these organisms were not thought to be of relevance to the aetiology of the pneumonia.

Blood cultures were obtained from 128 patients $(61 \%)$ of whom $73(57 \%)$ had received antibiotics. There were five positive blood cultures-two yielding Str pneumoniae, two Staph aureus, and one a viridans streptococcus. Thirty of the patients in the "no pathogen" group with negative blood cultures had not received antibiotics.

Only a small number of patients presented within five days of the onset of their illness, so only 10 throat swabs were collected for virus isolation. One of these yielded influenza A virus, and the rest were negative.

Paired or convalescent serum samples were obtained from 160 patients $(76 \%)$. Seventy-three infections were detected by this means; the commonest agent was $M$ pneumoniae (30). Almost as many infections with influenza A virus were found (22), but the other respiratory viruses (nine), Chlamydia psittaci, Cox burneti (six), and L pneumophila (three) were all much less common. Adequate specimens for serology were obtained from 74 $(69 \%)$ of the patients in whom no pathogen was detected. Patients from whom paired or convalescent serum had not been obtained had either died or did not attend for follow-up.

In 10 patients there were coexisting bacterial and viral or rickettsial infections (table 2). Eight of these involved influenza $\mathrm{A}$, and one each parainfluenza 
Table 2 Mixed infections

\begin{tabular}{lll}
\hline Bacterium & Associated pathogen & Number \\
\hline Streptococcus pneumoniae & Influenza A & 2 \\
Staphylococcus aureus & Influenza A & 3 \\
Staphylococcus aureus & Coxiella burneti & 1 \\
Haemophilus influenzae & Influenza A & 2 \\
Haemophilus influenzae & Parainfluenza & 1 \\
Klebsiella spp & Influenza A & 1 \\
\hline
\end{tabular}

and Cox burneti. No mixed infections involving $M$ pneumoniae were found.

The mean age of the patients was 54 years. The patients with mycoplasma pneumonia were younger (mean 39 years). Those with klebsiella pneumonia were older (mean 73 years), as were those with RSV infections (mean 70 years).

Antibiotics had been given to 120 patients $(57 \%)$ before they reached hospital (table 3). Sixteen

Table 3 Antibiotics given before admission to hospital

\begin{tabular}{lc}
\hline Antibiotic & Number of patients \\
\hline Ampicillin & 65 \\
Tetracycline & 25 \\
Co-trimoxazole & 20 \\
Cephalosporins & 9 \\
Penicillin & 5 \\
Cloxacillin & 5 \\
Others & 2 \\
Not recorded & 12 \\
Total & 137 \\
\hline
\end{tabular}

patients had received more than one course. Forty per cent of the patients with a proven bacterial infection had received antibiotics, as had $75 \%$ of those in whom a pathogen was identified by serology. This higher proportion was largely accounted for by the 26 patients with mycoplasma pneumonia who had received antibiotics, although only two of these had received an antibiotic that was appropriate (tetracycline or erythromycin). Of the 107 patients in whom no pathogen could be found, 55 $(51 \%)$ had received antibiotics before entering hospital.

Fifty-seven patients $(28 \%)$ had coexisting chronic chest disease, of which the most common was chronic bronchitis (39 patients). There were six patients with asthma, four with bronchiectasis, and eight with miscellaneous chest diseases. Eleven other

Table 4 Associated systemic disorder

\begin{tabular}{lcc}
\hline & Number & $\begin{array}{l}\text { Percentage of } \\
\text { total }\end{array}$ \\
\hline Cardiovascular disease & 16 & 8 \\
Central nervous system disease & 6 & 3 \\
Diabetes/endocrine disease & 8 & 4 \\
Connective tissue disorder & 4 & 2 \\
Previous non-pulmonary neoplasm & 9 & 4 \\
Others & 6 & 3 \\
Total & 49 & 23 \\
\hline
\end{tabular}

patients had suffered a previous episode of $\overrightarrow{0}$ pneumonia.

A coexisting systemic disease was found in $49 \frac{\overline{\bar{c}}}{\overline{\mathrm{C}}}$ patients $(23 \%)$ (table 4$)$. There were no patients with $\stackrel{\mathbb{Q}}{\Omega}$ a diagnosis of alcoholism in this series. There was no obvious association between chronic chest or systemic disease and any particular pathogen, although fewer of the patients with mycoplasma pneumonia had either chronic chest or systemic disease.

Eighty-seven patients $(42 \%)$ were regular smokers $\vec{x}$ at the time of diagnosis, $34(16 \%)$ were ex-smokers, and $63(30 \%)$ were non-smokers. There were rather $\infty$ fewer smokers in the group with mycoplasma or pneumonia $(25 \%)$. All three patients with Legion- 8 naires' disease were smokers.

Table 5 Mortality

\begin{tabular}{llc}
\hline Pathogen & $\begin{array}{l}\text { Number of } \\
\text { deaths }\end{array}$ & $\begin{array}{l}\text { Percentage of } \\
\text { pathogen } \\
\text { group }\end{array}$ \\
\hline Streptococcus pneumoniae & 2 & 8 \\
Staphylococcus aureus & 3 & 38 \\
Klebsiella spp & 1 & 33 \\
Legionella pneumophila & 2 & 67 \\
Mycoplasma pneumoniae & 1 & 3 \\
Influenza A* & 4 & 18 \\
Respiratory syncytial virus & 1 & 33 \\
No pathogen identified & 5 & 5 \\
\hline
\end{tabular}

*Includes two mixed infections with Staphylococcus aureus.

Seventeen patients ( 11 male, 6 female) died, giving an overall mortality rate for this group of patients of $8 \%$ (table 5). Of those who died $35 \%$ had associated chronic chest disease, and $53 \%$ had an associated systemic disorder. A high mortality was found in Legionnaires' disease (two out of three died) and in staphylococcal pneumonia (three out of eight), particularly when associated with infection with influenza $A$ virus. The one patient who died after mycoplasma pneumonia was thought to have died from a pulmonary embolus.

The mean duration of symptoms before admission to hospital is shown in table 6 . The majority of the $\widetilde{N}$ patients with bacterial pneumonia were admitted

Table 6 Duration of illness before admission

\begin{tabular}{lc}
\hline Pathogen & Mean duration of illness (days) \\
\hline Steptococcus pneumoniae & 5 \\
Staphylococcus aureus & 8 \\
Haemophilus influenzae & 13 \\
Klebsiella spp & 2 \\
Legionella pneumophila & 3 \\
Mycoplasma pneumoniae & 11 \\
Chlamydia psittaci & 16 \\
Coxiella burneti & 12 \\
Influenza A & 12 \\
Influenza B & 12 \\
Respiratory syncytial virus & 10 \\
No pathogen & 11 \\
\hline
\end{tabular}


within 10 days of the onset of their illness, whereas those with mycoplasma pneumonia, Q fever, and psittacosis tended to be admitted after a longer illness.

\section{Discussion}

The isolation rate for Str pneumoniae is lower in this series than in most others. Earlier investigators, such as Humphrey et al,,$^{3}$ isolated this organism in over $75 \%$ of their patients with pneumonia acquired in a North West London community. A later report, from Edinburgh, ${ }^{1}$ found Str pneumoniae in $44 \%$ of patients with pneumonia, although they included some patients with exacerbations of chronic bronchitis. More recent series have been described from the USA, where isolation rates for Str pneumonice have ranged from $39 \%$ to $53 \%{ }^{45}$

Differing bacteriological techniques may account for some of this variation. Positive sputum cultures are not always associated with clinical pneumonia, and sputum is often contaminated with organisms from the oropharynx. The interpretation of sputum cultures containing small numbers of organisms can thus be difficult. ${ }^{6}$ Transtracheal aspiration for the collection of sputum avoids these difficulties, but has not been widely used in the past and is not without morbidity. ${ }^{7}$ The homogenisation and dilution of sputum before culture generally produce a pure growth of pathogenic bacteria, and reduce the likelihood of culturing oropharyngeal contaminants. ${ }^{6}$ If only a few pathogens are present in the sputum, however, perhaps as a result of previous antibiotic therapy, this technique may give negative results.

Previous antibiotic therapy reduces considerably the chances of isolating a pathogen from both blood and sputum. ${ }^{8}$ Other studies have included a varying proportion of patients who had received antibiotics before attending hospital, and only Dorff et $a l^{5}$ excluded these from analysis. In the 107 patients in our series in whom no pathogens were detected, antibiotics had been given to over $50 \%$, and a further $25 \%$ were unable to produce sputum; it is possible therefore that many of these patients had bacterial pneumonia.

The presence of disorders lowering the defences of the respiratory tract may alter the range of pathogens detected. Others have included varying proportions of patients with chronic chest disease, and systemic illness, and alcoholism was present in over $20 \%$ of the patients with pneumonia in the series of Mufson et al, ${ }^{4}$ Fekety et al, ${ }^{9}$ Sullivan et al, ${ }^{10}$ and Dorff et al. ${ }^{5}$ This may have predisposed to an aspiration pneumonia in some of their patients. The incidence of systemic illness in the present study is lower than in others, and previous British series (such as that of
Bath et al) have included rather more patients with chronic bronchitis.

Pneumonias caused by Gram negative bacteria have been found in varying proportions, ranging from $2.4 \%$ in the series compiled by Mufson et al ${ }^{4}$ to $20 \%$ in that of Sullivan et al ${ }^{10}$ who attributed this high figure to the presence of associated disease in over $75 \%$ of his patients. Even higher proportions are found when hospital-acquired infections, as well as those acquired in the community, ${ }^{11}$ are considered. The age of patients may also have some influence on the frequency with which Gram negative bacteria are isolated from patients with pneumonia; an investigation of the aetiology of pneumonia in elderly patients (admitted from a nursing home) found klebsiella pneumonia in $40 \%{ }^{12}$ The three patients of ours who had this infection were over 60 years of age.

Staphylococcal pneumonia was an uncommon pathogen in this series, as in most others. However its high mortality, particularly when following infection with influenza A was confirmed-three out of the four deaths in patients under 40 were attributable to staphylococcal pneumonia and in two of these there was evidence of influenza A infection.

We found 10 patients in whom there was evidence of both bacterial and viral or rickettsial infection.

Influenza $A$ was the virus most commonly associated with bacterial infection, and neither RSV nor influenza B virus infections were detected in conjunction with a definite bacterial pneumonia. Probably the incidence of bacterial pneumonia complicating virus infection would have been higher than the $29 \%$ detected in this series had fewer of these patients had antibiotic treatment before reaching hospital.

There were 22 patients in whom virus infections alone were found. There were no distinctive clinical features and antibiotics had been given to all but three of them, and so an associated bacterial infection may well have occurred.

RSV is a common cause of pneumonia and bronchiolitis in infants, but does not appear frequently in adult series. Three of our patients showed evidence of a recent RSV infection. Two of them could have had a bacterial pneumonia in addition since they had received antibiotics, but in one patient (who subsequently died) no bacterial pathogen could be identified despite adequate cultures, and it is likely that this patient had a pure viral pneumonia caused by RSV. Overall $15 \%$ of the patients in this series had serological evidence of a recent infection with influenza virus, RSV, or parainfluenza virus; the proportion of patients with virus infection might have been higher had it been possible to look for infection with other viruses such as 
rhinoviruses or coronaviruses.

Infections with $M$ pneumoniae were found in 30 patients $(14 \%)$, which is a higher proportion than in other series of civilian adult propulations. Bath et al ${ }^{1}$ found very few infections with this agent, but their study was compiled before a specific antibody assay was available, and the exclusive use of cold agglutinins is known to underestimate the incidence of infection caused by $M$ pneumoniae. ${ }^{15}$ Using a specific serological test, Mufson et $a l^{4}$ found $M$ pneumoniae in $4 \%$ of their patients, and Fekety et al ${ }^{9}$ in $8 \%$, but neither group of workers concluded that this organism was a significant cause of pneumonia. The mean age of our patients with mycoplasma pneumonia was 39 years, rather younger than average for the whole series, and this organism in fact accounted for $28 \%$ of pneumonias in patients under 50. There were epidemics in the United Kingdom in 1974-75 and 1978-79,16 and during these periods we found that up to one half of patients had pneumonia caused by this agent.

Neither Coxiella burneti nor Chlamydia psittaci were very common, and they have been found only rarely in other comparable series of civilian adults with pneumonia. Nevertheless they should be tested for routinely because a relevant contact history may not be obtained. Legionella pneumophila was detected in only three patients, none of whom had been abroad in the period before the onset of their illness, and it is likely that these infections were acquired locally. The mortality was high in these patients, as in other published accounts of Legionnaires' disease. This organism does not appear to be a common cause of pneumonia in this part of Britain.

Although this is a study of patients whose pneumonia was acquired outside hospital, it is of a selected group. They had been referred to hospital for reasons such as the severity of their illness, the development of complications, doubts about the diagnosis, and because adequate nursing care could not be provided at home. Patients who have been treated at home and who have responded well to treatment may well have a different spectrum of pathogens, perhaps with a higher frequency of Streptococcus pneumoniae and so a hospital-based study is unlikely to have given an indication of the frequency of the various pathogens causing pneumonia in the community.

We would like to thank the many nursing staff and $\frac{\widehat{\Phi}}{\mathrm{D}}$ house physicians at Frenchay Hospital who diligently collected the specimens. We also thank the staff of the Public Health Laboratories, Bristol and $\overrightarrow{0}$ the Microbiology Department, Frenchay Hospital, $\vec{\oplus}$ for their assistance with the processing of specimens.

\section{References}

${ }^{1}$ Bath JCL, Boissard GPB, Calder MA, Moffat MAJ. Pneumonia in hospital practice in Edinburgh 1960-1962. ن Br J Dis Chest 1964;58:1-16.

${ }^{2}$ McDade JE, Shepard CC, Fraser DW et al. Legionnaires' Disease: description of an epidemic of pneumonia. N Engl J Med 1977;297:1197-203.

${ }^{3}$ Humphrey JH, Joules H, Van der Walt ED. Pneumonia in North West London. Thorax 1948;3:112-21.

${ }^{4}$ Mufson MA, Chang V, Gill V, Wood SC, Romansky MJ. Role of viruses, mycoplasmas and bacteria in acute pneumonia in civilian adults. Am J Epidemiol 1967;86: 526-44.

${ }^{5}$ Dorff GJ, Rytel MW, Farmer SG, Scanlon G. Etiologies and characteristic features of pneumonias in a municipal hospital. Am J Med Sci 1973;266:349-58.

${ }^{6}$ Dixon JMS, Miller DC. The value of dilute inocula in cultural examination of sputum. Lancet 1965;2:1046-8.

${ }^{7}$ Spencer CD, Beaty HN. Complications of transtracheal aspiration. $N$ Engl J Med 1972;286:304-6.

${ }^{8}$ Spencer RC, Philp JR. Effects of previous antimicrobial therapy on bacteriological findings in patients with primary pneumonia. Lancet $1973 ; 2: 349-50$.

${ }^{9}$ Fekety FR, Caldwell J, Gump D et al. Bacteria, viruses and mycoplasmas in acute pneumonias in adults. Am Rev Respir Dis $1971 ; 104: 499-507$.

${ }^{10}$ Sullivan RJ, Dowdle WR, Marine WM, Hierholzer JC. Adult pneumonia in a general hospital. Arch Intern Med 1972;129:935-42.

${ }^{11}$ Burns MW, Devitt L, Bryant DH. Pneumonia in a city hospital. Med J Aust 1976;2:787-91.

${ }^{12}$ Garb JL, Brown RB, Garb JR, Tuthill RW. Differences in etiology of pneumonias in nursing home and community patients. JAMA 1978;240:2169-72.

${ }^{13}$ Schwarzman SW, Adler JL, Sullivan RJ, Marine WM. 음 Bacterial pneumonia during the Hong Kong influenza epidemic of 1968-1969. Arch Intern Med 1971;127: 1037-41.

${ }_{14}$ Stuart-Harris $\mathrm{CH}$, Schild GC. Influenza: the viruses and $\mathrm{N}$ the disease. London: Edward Arnold, 1976:103-6.

15 Purcell RH, Chanock RM. Role of Mycoplasmas in human N respiratory disease. Med Clin North Am 1967;51:791- N 802.

${ }^{16}$ Noah ND, Urquhart AM. Epidemiology of Mycoplasma pneumoniae infection in the British Isles 1974-9. J Infection 1980;2:191-4. 